\title{
COMPARISON OF PROCEDURES FOR EVALUATION OF EFFECT OF WELDING THERMAL CYCLE ON IMPACT TOUGHNESS OF HAZ METAL OF WELDED JOINTS FROM LOW-ALLOY STEELS
}

\author{
V.D. POZNYAKOV, L.I. MARKASHOVA, S.L. ZHDANOV, E.N. BERDNIKOVA, \\ A.V. ZAVDOVEEV and A.A. MAKSIMENKO \\ E.O. Paton Electric Welding Institute, NASU \\ 11 Kazimir Malevich Str., 03680, Kiev, Ukraine. E-mail: office@paton.kiev.ua
}

\begin{abstract}
One of the most important indices of mechanical properties, which together with other factors determine the quality and working capacity of the welded joints, is impact toughness. Impact toughness is characterized by material capability to absorb mechanical energy in process of deformation and fracture under impact load effect. This paper carries a comparative evaluation of effect of welding on impact toughness of HAZ metal of specimens, produced from bead-onplate tests, and reference ones, treated on welding thermal cycle, from steel 10G2FB. It is determined that effect of the welding thermal cycles on impact toughness indices of HAZ metal of welded joints from steel 10G2FB is ambiguous. Rapid decrease of $K C U$ and $K C V$ values is observed at $w_{6 / 5}<6{ }^{\circ} \mathrm{C} / \mathrm{s}$ cooling rates. Increase of cooling rate provides for rise of HAZ metal impact toughness and in some cases it reaches $K C U$ and $K C V$ values of base metal. Therefore, it is a good correlation of the values of impact toughness between the specimens, treated on welding thermal cycle, and specimens, produced from welded joints. It is insignificant difference in nature of their fracture. 7 Ref., 2 Tables, 6 Figures.
\end{abstract}

Ke y w or d s: low-alloy steel, impact toughness, welding thermal cycle, bead-on-plate test, heat-affected zone, structure, fracture surface

One of the most important indices of mechanical properties, which together with other factors determine the quality and working capacity of the welded joints, is impact toughness. Impact toughness is characterized by material capability to absorb mechanical energy in process of deformation and fracture under impact load effect [1].

Since different areas of the welded joints (weld metal, heat-affected zone) can, respectively, vary on chemical composition, structure and properties then impact toughness is determined for each of indicated areas. Sampling, manufacture and impact bend testing of the specimens is carried out on GOST 6996-66. A notch, depending on purpose of the test, is located along weld metal, along fusion zone and in different areas of near-weld zone at some distance from fusion line. The notch can be of V- or U-shape. In accordance with this, impact toughness has $K C V$ or $K C U$ indices. Mostly, such an approach is used in impact bend testing of welded joints at certification of engineering welding processes and welders as well at final stage of checking the developed welding procedures.

Somewhat other methods are used in scientific-research and experimental works on study the welding effect on base metal, including evaluation of this ef- fect on impact toughness of metal of heat-affected zone (HAZ).

One of them, namely «Bead-on-plate test method for determination of allowable modes of arc welding and surfacing» (GOST 13585-68) is used for evaluation of change of base metal mechanical properties, promoted by welding thermal cycle directly in HAZ adjacent to fusion zone as well as other areas of HAZ [2]. An essence of this method lies in deposition of beads on solid or composite plates of examined steels at different heat input and further determination of impact toughness and strength properties of HAZ. At that, the data on effect of heat input on impact toughness of metal in HAZ complete resolidification area is of the most interest. In this case, the notch on the specimens is made in such a way so as its bottom locates on a bead axis below the fusion line at not more than $0.5 \mathrm{~mm}$ distance to base metal side. The peculiarity of indicated specimens is the fact that in the impact bend testing only beginning of fracture proceeds in the controlled zone, while its propagation proceeds along the base metal. At that, the lower welding heat input is the larger amount of base metal will be involved in fracture. Based on this, it can be assumed that bean-on-plate test procedure should be sufficiently good in describing a capability of HAZ metal to 
fracture nucleation resistance. However, accuracy of information in a question how such metal will resist fracture propagation raises doubts. In particular, it is related to the cases when relatively small welding modes are used in bead-on-plate deposition, thus promoting small HAZ width, as well as when the indices of impact toughness of steel significantly exceed impact toughness of HAZ metal.

Effect of welding on base metal can be also evaluated using a method at which thermal action on metal is carried out without application of welding (GOST 23870-79) [3-6]. In this case, the billets (ingots of specific size) from studied steel are heated and cooled on mode, comparable with welding thermal cycle (WTC). For this, the billets are heated to set temperature by means of passing current and then forced cool. Such action on metal provides formation in it of approximately the same structure as in HAZ metal of the welded joints subjected to similar thermal action in welding. Since for WTC simulation the whole section in the middle of the billets is heated and cooled uniformly, then it can be supposed that metal impact toughness in different areas of this section will be sufficiently close. Thus, the results of specimen testing can provide more reliable information on capability of HAZ metal of that or another steel to fracture propagation resistance in impact bending.

Taking into account mentioned above, the aim of present work lies in carrying out a comparative evaluation of welding effect on impact toughness of HAZ metal of specimens, produced from bead-on-plate test and base metal billets treated on WTC, by example of one of low-alloy steels.

Investigation procedures. Plates of $250-450 \mathrm{~mm}$ width and $600 \mathrm{~mm}$ length were used for bead-on-plate test method. They were cut in such a way that bead direction in further deposition coincides with rolling direction. Before welding an average part of the plate, designed for bead deposition, was cleaned from scale and corrosion to general width of $80 \mathrm{~mm}$ (40 $\mathrm{mm}$ in each side from a deposition axis).

The bead was deposited along longitudinal symmetry axis of the plate (Figure 1) on modes providing change of cooling rate in $600-500{ }^{\circ} \mathrm{C}\left(w_{6 / 5}\right)$ temperature range from 3 to $30^{\circ} \mathrm{C} / \mathrm{s}$. Such metal cooling intensity in HAZ overheating area is typical for the majority of arc welding processes, i.e. automatic submerged arc, gas-shielded mechanized and manual welding with stick electrodes. The parameters of welding modes and corresponding rates of cooling of HAZ metal of bead-on-plate tests are given in Table 1.

Bead deposition was carried out in a jig by $\mathrm{Sv}$ 08GA wire of $4 \mathrm{~mm}$ diameter using AN-348 flux with reverse polarity direct current at $27{ }^{\circ} \mathrm{C}$ ambient tem-
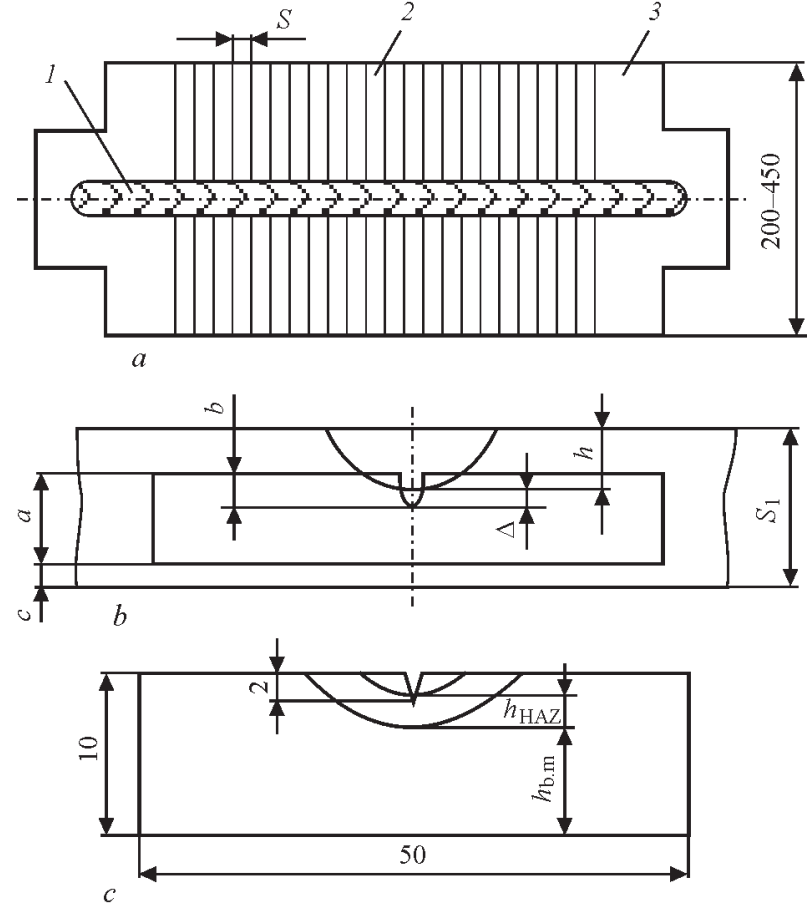

Figure 1. Bead-on-plate test with deposit (a), scheme of cutting the specimens for impact bend testing $(b)$ and designation of areas of welded joint, which are included in impact specimen $(c): 1-$ deposited bead; 2 - compound bars; 3 - run-on plate; $h$ - area with deposited metal; $h_{\mathrm{HAZ}}-\mathrm{HAZ}$ area; $h_{\mathrm{b} . \mathrm{m}}$ - base metal area

perature. No wire oscillation was allowed. After bead deposition was finished the plate remained in the jig till complete cooling of the specimen.

The specimens for mechanical tests were made from the plates prepared and deposited using the method indicated above. These specimens should correspond to the requirements of GOST 13585-68, therefore the microsections were made from beadon-plate tests at the initial stage. They were used for determination of bead parameters (bead width, bead reinforcement, penetration depth and HAZ parameters). This allowed determining a thickness of metal layer, which should be removed before specimens manufacture.

Bars of $13 \times 13 \times 150 \mathrm{~mm}$ size made from studied steel were used for investigations applying billets treated on welding thermal cycle. Their heat treatment was carried out on MSR-75 unit, developed at the E.O. Paton Electric Welding Institute. Heating of the bars was carried out by passing current up to $1200-1300^{\circ} \mathrm{C}$ temperature (corresponds to HAZ metal overheating

Table 1. Modes of deposition and cooling rate for HAZ metal of bead-on-plate tests from $18.7 \mathrm{~mm}$ thick plate

\begin{tabular}{|c|c|c|c|c|}
\hline$I_{\mathrm{w}}, \mathrm{A}$ & $U_{\mathrm{a}}, \mathrm{V}$ & $v_{\mathrm{w}}, \mathrm{m} / \mathrm{h}$ & $Q_{\mathrm{w}}, \mathrm{kJ} / \mathrm{cm}^{2}$ & $w_{6 / 5},{ }^{\circ} \mathrm{C} / \mathrm{s}$ \\
\hline $580-600$ & $34-38$ & 12.9 & 50.6 & 3 \\
\hline $580-600$ & $34-38$ & 20.0 & 35.7 & 6 \\
\hline $580-600$ & $34-38$ & 23.7 & 28.6 & 10 \\
\hline $380-400$ & $30-32$ & 20.0 & 20.4 & 20 \\
\hline $380-400$ & $30-32$ & 23.7 & 17.0 & 30 \\
\hline
\end{tabular}


area of welded joints) at $170-200^{\circ} \mathrm{C}$ rate. At this temperature they were hold approximately during $2 \mathrm{~s}$ and then were cooled. Copper jaws of the unit were cooled using flowing water for providing bars' cooling at $w_{6 / 5}$ from 2.5 to $7.5^{\circ} \mathrm{C} / \mathrm{s}$. More intensive rates of specimen cooling were reached as a result of additional blowing of the specimens by inert gas that allowed variation of $w_{6 / 5}$ from 8 to $30^{\circ} \mathrm{C} / \mathrm{s}$ due to change of value of gas consumption.

Additionally, HAZ metal impact toughness was evaluated based on results of testing of the specimens produced from butt joints of $18.7 \mathrm{~mm}$ thickness with V-groove preparation (C21 on GOST 2564-80 and 14771-76), made by manual coated electrode welding and mechanized $\mathrm{CO}_{2}$ welding. In this case cutting of the specimens and making of a notch was carried out on GOST 6996-66.

Manual arc welding was performed by ANP-10 grade electrodes of $4 \mathrm{~mm}$ diameter on the following mode, i.e. $I_{\mathrm{w}}=160-170 \mathrm{~A} ; U_{\mathrm{a}}=24-25 \mathrm{~V} ; v_{\mathrm{w}}=8.5-$ $9.0 \mathrm{~m} / \mathrm{h}$, which provided intensity of cooling of welded joint $\mathrm{HAZ}$ metal with $w_{6 / 5}=30{ }^{\circ} \mathrm{C} / \mathrm{s}$ rate. Fluxcored wire Megafil 821R of $1.2 \mathrm{~mm}$ diameter and the next mode were used for mechanized welding, namely $I_{\mathrm{w}}=180-200 \mathrm{~A}, U_{\mathrm{a}}=28-30 \mathrm{~V}, v_{\mathrm{w}}=13.5-15.0 \mathrm{~m} / \mathrm{h}$. At that, the cooling rate at $\mathrm{HAZ}$ metal area made $21^{\circ} \mathrm{C} / \mathrm{s}$. In all cases welding was carried using reverse polarity direct current.

The rate of heating and cooling of the specimens was controlled using chromel-alumel thermal couple of $0.5 \mathrm{~mm}$ diameter, and evaluated on results of processing of oscillograms, recording of which was made
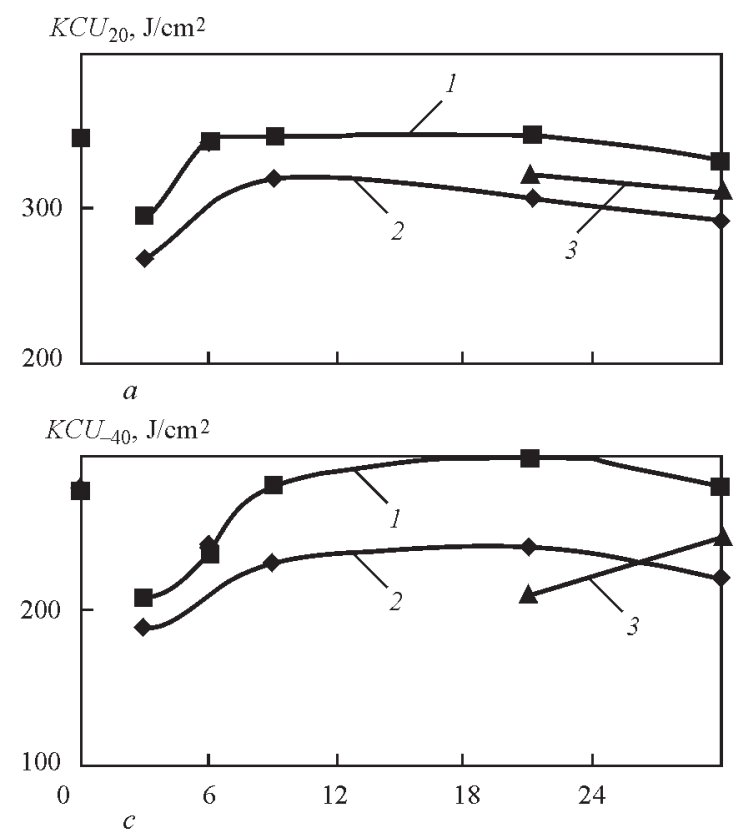

using 117/1 oscillograph in temperature — time coordinates.

Specimens of 10x10x55 mm size (type VI with round notch and type IX with acute notch on GOST 6996-66) were made for determination of impact toughness of HAZ metal from beat-on-plate tests and billets treated on WTC. The specimens were mechanically cut. The specimens were cooled by emulsion in order to prevent metal heating.

Testing of the specimens was carried out at 20 and $-40{ }^{\circ} \mathrm{C}$ temperature (not less than three specimens at each temperature). Impact toughness was determined in area of complete resolidification of HAZ metal $\left(K C U_{+20}, K C U_{-40}, K C V_{+20}, K C V_{-40} \mathrm{~J} / \mathrm{cm}^{2}\right)$.

Structures of fracture surface of the specimens were examined with the help of scanning electron microscope of SEM 515 grade of Philips Company (the Netherlands).

Results of investigations and their discussion. High-strength structural niobium and vanadium micro-alloyed steel having $18.7 \mathrm{~mm}$ thickness and the following composition (wt.\%) was selected as an object for investigation: $0.08 \mathrm{C}$; $0.25 \mathrm{Si} ; 1.57 \mathrm{Mn}$; $0.19 \mathrm{Mo} ; 0.05 \mathrm{Nb} ; 0.05 \mathrm{~V} ; 0.032 \mathrm{Al} ; 0.006 \mathrm{~N} ; 0.007$ $\mathrm{S} ; 0.013 \mathrm{P}$. In as-delivered condition (controlled rolling) steel has the following mechanical properties: $\sigma_{\mathrm{v}}=531-581 \mathrm{MPa} ; \sigma_{\mathrm{t}}=610-660 \mathrm{MPa} ; \delta_{5}=24.8-$ $26.3 \% ; \psi=62.0-64.8 \%, K C U_{+20}=340-350 \mathrm{~J} / \mathrm{cm}^{2}$; $K C U_{-40}=280-320 \mathrm{~J} / \mathrm{cm}^{2} ; K C V_{+20}^{+20}=300-330 \mathrm{~J} / \mathrm{cm}^{2}$, $K C V_{-40}^{-40}=190-210 \mathrm{~J} / \mathrm{cm}^{2}$.

It is determined that steel impact toughness is changed under the effect of welding thermal cycle based on results of testing the specimens, produced
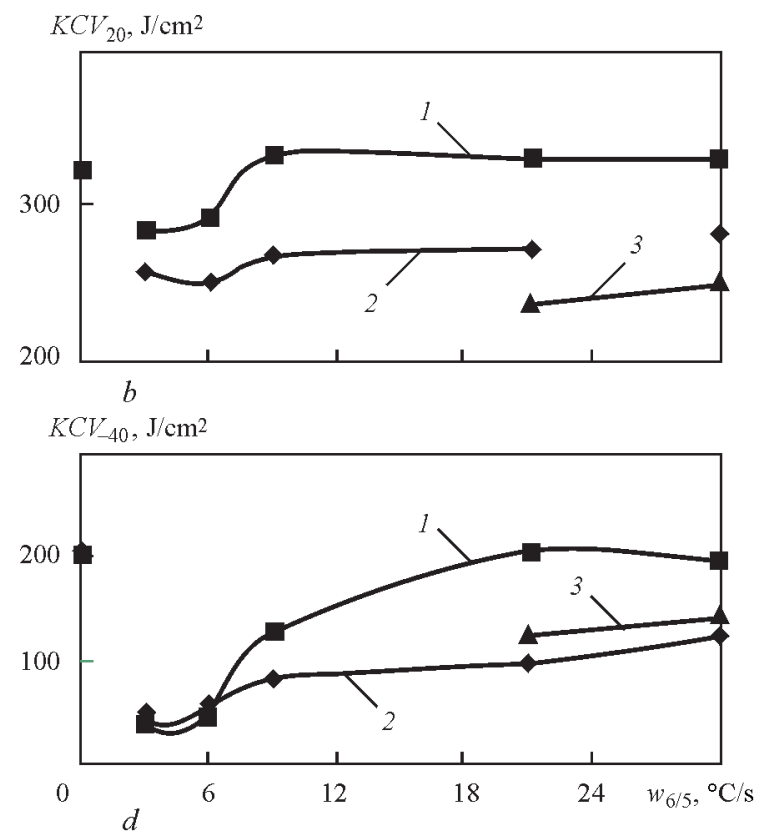

Figure 2. Effect of cooling rate on impact toughness of specimens, produced from bead-on-plate tests (1); WTC-treated billets (2); welded joints (3) (values of impact toughness indices of base metal are given in point $w_{6 / 5}=0$ ) 
Table 2. Nature of fracture and size of microrelief elements of fracture surfaces in zone of main crack propagation

\begin{tabular}{|c|c|c|c|c|c|}
\hline \multicolumn{2}{|c|}{ Fracture nature } & Welded joint & WTC simulation & Bead-on-plate test & Base metal \\
\hline \multirow{3}{*}{ Ductile } & $V_{\mathrm{a}}, \%$ & $5-7$ & 5 & 100 & 15 \\
\cline { 2 - 6 } & $d_{\mathrm{p}}, \mu \mathrm{m}$ & $1-3$ & $1-3$ & $1-10$ & $1-10$ \\
\cline { 2 - 6 } & $D_{\mathrm{p}}, \mu \mathrm{m}$ & - & - & $20-70 \times 70-250$ (av. $45 \times 160)$ & $10-70 \times 20 \ldots-150(\mathrm{av} .40 \times 85)$ \\
\hline \multirow{3}{*}{ Brittle intergrain } & $V_{\mathrm{a}}, \%$ & 95 & 95 & - & 5 \\
\cline { 2 - 6 } & $D_{\mathrm{f}}, \mu \mathrm{m}$ & $10-20$ & $20-60$ & - & $10-25$ \\
\hline Secondary microcracks & $L_{\mathrm{cr}}, \mu \mathrm{m}$ & $5-10$ & $5-30$ & - & - \\
\hline
\end{tabular}

from bead-on-plate tests, from welded joints as well as from heat-treated billets of studied steel. It is usually reduced (Figure 2) in relation to base metal.

The most obvious reduction of impact toughness indices of metal in HAZ overheating area is observed in the case when deposition of plates (in production of bead-on-plate tests) was carried out on modes providing high heat input $\left(Q_{\mathrm{w}}=50.6-35.7 \mathrm{~kJ} / \mathrm{cm}^{2} ; w_{5 / 6}=\right.$ $=3-6^{\circ} \mathrm{C} / \mathrm{s}$ ), and billet heat treatment is done on welding thermal cycles, providing indicated cooling rate of metal in $500-600{ }^{\circ} \mathrm{C}$ temperature range. It should be noted that under such cooling conditions the indices of impact toughness of specimens, produced from bead-on-plate tests, and billets treated on welding thermal cycle are sufficiently close.

Decrease of welding heat input provides for rise of $w_{6 / 5}$ (Table 1) and increase of indices of impact toughness of HAZ metal. The most obvious increase of $K C U$ and $K V C$ indices (virtually till the base metal level) is observed in the case, when the investigations were carried out using the specimens, produced from bead-on-plate tests, deposition of which was carried out on modes providing $Q_{\mathrm{w}} \leq 28.6 \mathrm{~kJ} / \mathrm{cm}^{2}$ $\left(w_{6 / 5} \geq 10^{\circ} \mathrm{C} / \mathrm{s}\right)$. Under the same cooling conditions the impact toughness of specimens, treated on WTC, is also rises, however, in all cases it is lower than that of the specimens, produced from base metal and bead-on-plate tests.

As indicated in work [7], variation of impact toughness indices of $10 \mathrm{G} 2 \mathrm{FB}$ steel as a result of effect of welding thermal cycles on it is related with a change of phase-structural composition of HAZ metal, namely, with formation in it of coarse grain ferrite-bainite structure at $w_{6 / 5} \leq 10^{\circ} \mathrm{C} / \mathrm{s}$ and fine-grain bainite structure at $w_{6 / 5} \geq 10^{\circ} \mathrm{C} / \mathrm{s}$.

In order to explain the differences between the impact toughness indices of the specimens, produced from bead-on-plate tests, and bars, treated on WTC, it is necessary to consider what areas of welded joint are included in impact specimens and what are their relationship in fracture zone.

The following can be noted as for the specimens, produced from the bars treated on WTC. Since the middle part of the specimen, where the notch was subsequently made, was uniformly heated and cooled in process of heat treatment, it had homogeneous on composition structure formed in it. Respectively, in this case, fracture of the specimen took place along the metal which has approximately similar mechanical properties. As it is schematically shown in Figure 1, the impact specimen, produced from bead-onplate tests, partially consists of a layer of deposited metal, HAZ and base metal. The deposited metal does not participate in specimen fracture, since it includes the notch. Since impact loads fall on HAZ and base metal, then fracture of the specimen takes place directly along this areas.

We are to consider a variation of relationship of area width, corresponding to HAZ $\left(h_{\mathrm{HAZ}}\right)$ and base metal $\left(h_{\mathrm{b} . \mathrm{m}}\right)$ depending on welding heat input. Such data are shown in Figure 3. They indicate that relationship between $h_{\mathrm{HAZ}}$ and $h_{\mathrm{b} . \mathrm{m}}$ makes 0.9 in zone of fracture of impact specimens, produced from beadon-plate tests, deposition of which is carried out using large heat input. Respectively, in this case, fracture of the specimen will mainly take place along HAZ metal as in the specimens treated on welding thermal cycle. Therefore, it is not surprisingly that the indices of impact toughness of the specimens, produced from bead-on-plates and heat-treated billets, virtually match.

HAZ width reduces with decrease of welding heat input $\left(w_{6 / 5}\right.$ rise $)$. In this connection $h_{\mathrm{HAZ}} / h_{\mathrm{b} . \mathrm{m}}$ relationship is also reduced. At $Q_{\mathrm{w}} \leq 28.6 \mathrm{~kJ} / \mathrm{cm}^{2}$

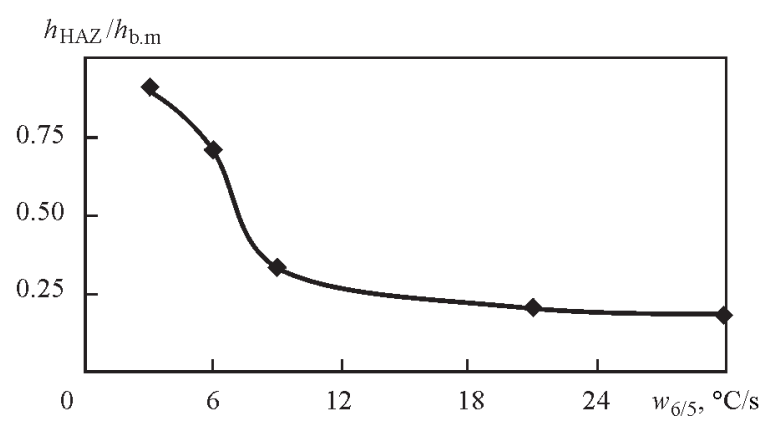

Figure 3. Effect of cooling rate of bead-on-plate tests on relationship between width of areas of HAZ metal $\left(h_{\mathrm{HAZ}}\right)$ and base metal $\left(h_{\mathrm{b} . \mathrm{m}}\right)$, taking part in fracture of impact specimens 


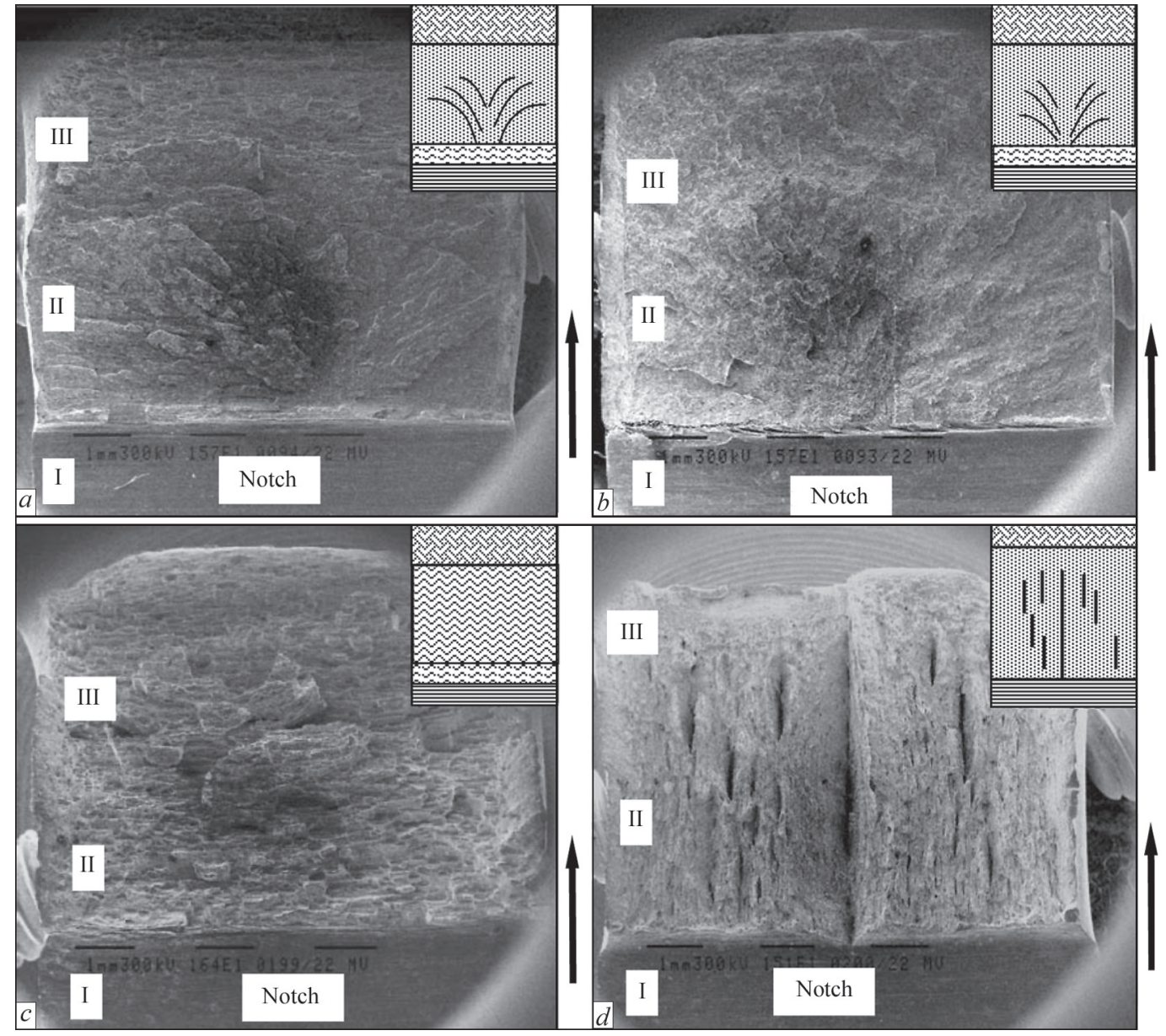

Figure 4. General view of break surface on fracture zones of specimens, produced from: welded joint $(a)$; billets treated on WTC $(b)$; bead-on-plate test $(c)$; base metal $(d), \times 16$ (schematic presentation of the breaks are in the upper right part of the picture) (see designations in the text)

$\left(w_{6 / 5} \geq 10^{\circ} \mathrm{C} / \mathrm{s}\right)$ a fraction of HAZ in specimen fracture reduces virtually to $25 \%$. Respectively, the main fracture of impact specimens took place on base metal. This, apparently, can be an explanation of the fact that the indices of impact toughness of specimens, produced from bead-on-plate tests, welding of which was carried out at lower modes, are comparable with impact toughness indices of base metal.

As for fracture of the specimens, produced from welded joints, then they mainly fracture on HAZ metal. At that, all HAZ areas were involved in fracture, namely high-temperature as well as low-temperature. Therefore, the impact toughness indices of such specimens are significantly differ from $K C U$ and $K V C$ indices of the specimens, produced from bead-on-plate tests, and have relatively good correlation with similar properties of heat-treated specimens.

The dependence of obtained results is verified by the fractographic examinations of the specimen fractures. Their aim lied in comparison of fracture nature (transcrystalline and intercrystalline; brittle; quasi-brittle; ductile or mixed) of welded joint metal on fracture zones (I - zone of fracture necleous near notch; II main crack propagation; III - zone of break) as well as analysis of fracture structure of welded joints taking into account parameters of microrelief elements of fracture surface: size of chip facets $d_{\text {fac }}$, pits of ductile constituent (disperse $d_{\mathrm{p}}$, coarse $D_{\mathrm{p}}$ ) length of secondary cracks $l_{\text {cr }}$ General view of specimen fractures is given in Figure 4. The arrows show fracture direction.

Since zone I (near notch) and zone III (break) in all investigated specimens are characterized by similar ductile type of fracture, further they are not studied in details. It is appeared to be more reasonable to carry out a comparative analysis in zone of main crack propagation (II), where significant difference in fracture nature was observed.

Analysis of specimen fracture showed that according to macrorelief the fracture surfaces in zone II of the specimens, produced from WTC treated billets, and one from welded joints, are similar. In both cases the radial scars (Figure 4, $a, b$ ) propagating from fracture nucleus match with general direction of crack propagation.

Further examination of micropeculiarities of the fracture surfaces in zone of main crack showed that fracture of the specimens, produced from welded joints, and ones from WTC treated billets, can be 
characterized as brittle intergrain chip (Table 2; Figure 5; Figure $6, a, b$ ) with local areas of ductile constituent (disperse pits of $d_{\mathrm{p}}=1-3 \mu \mathrm{m}$ size, volume fraction $V_{\mathrm{f}} \sim 5 \%$ ). Such details of microrelief as the areas of ductile constituent indicate a local plastic deformation, i.e. development of a brittle chip in adjacent grain can take place with obvious plastic deformation in a transient zone.

Analysis of fracture nature of the specimens, produced from welded joints, showed that size of the chip facets on fracture surface makes $d_{\text {fac }} \sim 10-20 \mu \mathrm{m}$, size of single secondary microcracks $l_{\text {cr }} \sim 5-10 \mu \mathrm{m}$ (Figure $6, a$ ).

Secondary microcracks of 5-10 $\mu \mathrm{m}$ length were also observed on fracture surface of the specimens, produced from WTC treated billets. However, the chip facets in such specimens are 2-3 times larger, than in the specimens, produced from welded joints, they achieve 20-60 $\mu \mathrm{m}$ size, approximately (Figure $6, b)$. It can be explained by the fact that fracture of the specimens, produced from WTC treated billets, takes place on metal with coarse grain, which is typical for HAZ overheating area of welded joint, and along all HAZ areas in the specimens, made from welded joints.

Fracture of the specimens, produced from bead-onplate tests and base metal, takes place completely in another way. Analysis of fracture of these specimens

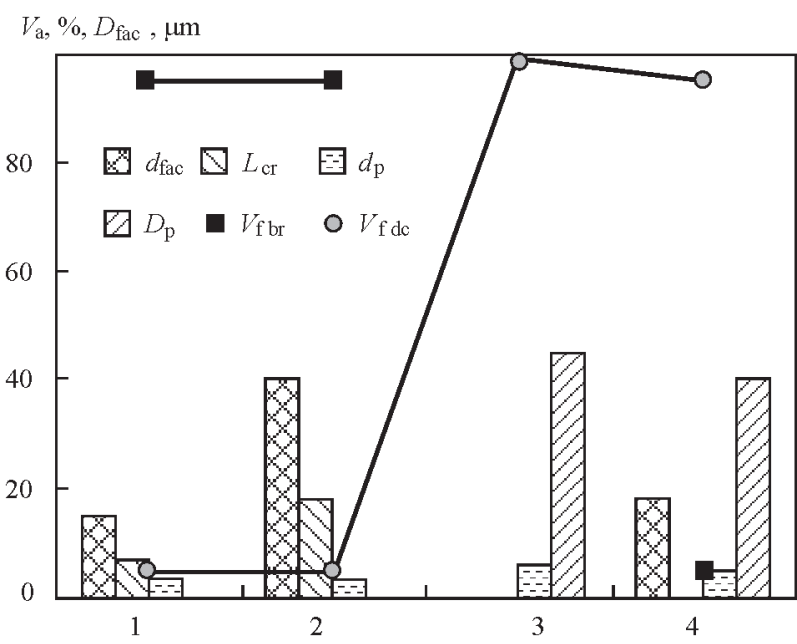

Figure 5. Change of volume fraction of brittle $\left(V_{\mathrm{fb}}, \%\right.$ and ductile $\left(V_{\mathrm{fdc}}, \%\right)$ fracture, size of facets $\left(d_{\mathrm{fac}}, \mu \mathrm{m}\right)$ of brittle intergrain chip and pits $\left(d_{\mathrm{p}}, D_{\mathrm{p}}, \mu \mathrm{m}\right)$ of ductile fracture, length of secondary cracks $\left(L_{\mathrm{cr}}, \mu \mathrm{m}\right)$ in fracture of specimens, produced from: welded joint (1); billets treated on WTC (2); bead-on-plate test (3); base metal (4)

showed that a ductile pit type of fracture (Figure 6, c, $d$ ) is observed on their surface in both cases. The difference lies only in the fact that fiber fracture surface of the specimens, produced from bead-on-plate tests, is characterized by expressed splitting on displaced levels in transverse direction of main crack propagation (Figure 4,c), and fracture of the base metal has a fiber-banded structure in longitudinal direction (Figure $4, d)$. Apparently, it is related with the fact that the
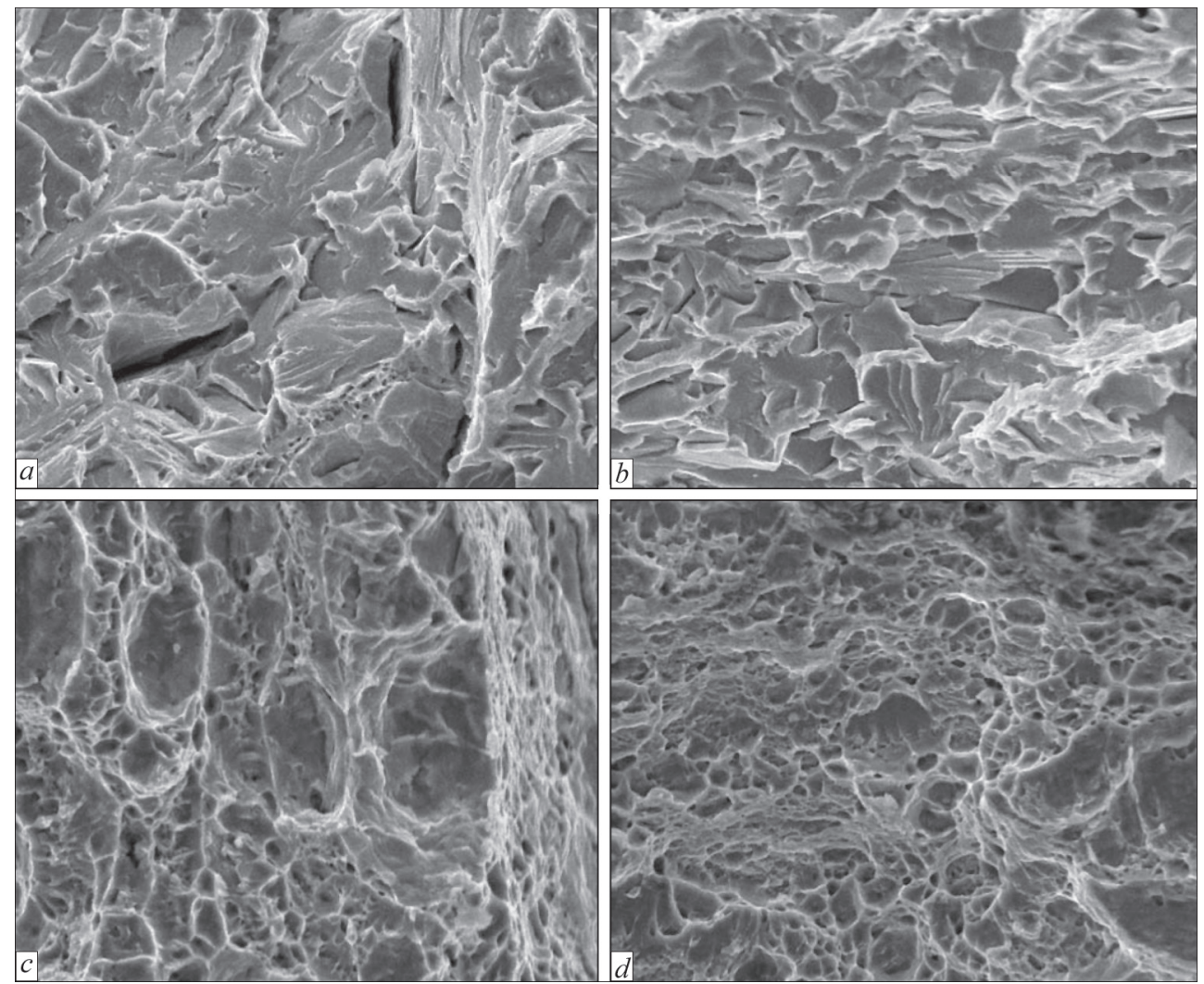

Figure 6. Nature of fracture in main crack zone: $a, b-$ brittle transcrystalline chip in fracture of specimens, produced from welded joint $(a)$, and treated on WTC method $(b) ; c, d$ - ductile fracture of specimen from bead-on-plate test $(c)$ and base metal $(d), \times 1550$ 
specimens, produced from bead-on-plate tests, and base metal, were cut in directions different in relation to rolling. It is not surprisingly, that a fracture nature of such specimens is approximately similar, since, according to mentioned above, and, as can be seen from Figures 1 and 3, development of the main crack in the specimens, produced from bead-on-plate tests, welding of which was carried out at low heat input, mainly takes place along the base metal.

\section{Conclusions}

1. Effect of welding thermal cycles on impact toughness indices of HAZ metal of welded joints from 10G2FB steel is ambiguous. Rapid decrease of $K C U$ and $K C V$ values is observed at cooling rates $w_{6 / 5}<6{ }^{\circ} \mathrm{C} / \mathrm{s}$. Increase of cooling rate provides for rise of impact toughness of HAZ metal and in some cases it reaches $K C U$ and $K C V$ values of base metal.

2. Reduction of welding heat input promotes for increase of cooling rate $w_{6 / 5}$ of HAZ metal of beadon-plate tests, and decreases the width of this area in the joint.

3. Low rates of cooling of HAZ metal $\left(w_{6 / 5}<{ }^{\circ} \mathrm{C} / \mathrm{s}\right)$, typical for welding processes, carried out at increased heat input $\left(Q_{\mathrm{w}}>35 \mathrm{~kJ} / \mathrm{cm}^{2}\right)$, promotes for fracture of the specimens mainly on HAZ metal, and $K C U$ and $K C V$ indices of the specimens, produced from beadon-plate tests and treated on welding thermal cycle, have insignificant difference.

4. Fracture of the specimens, produced from beadon-plate tests, with rise of $w_{6 / 5}$ to $10{ }^{\circ} \mathrm{C} / \mathrm{s}$ and above $\left(Q_{\mathrm{w}}<30 \mathrm{~kJ} / \mathrm{cm}^{2}\right)$ mainly takes place along the base metal. Due to this the difference between the indices of impact toughness of the specimens, produced from bead-on-plate tests, and one from billets treated on welding thermal cycle, becomes noticeable.

5. A good correlation is found for the values of impact toughness between the specimens, produced from welded joints and billets treated on welding thermal cycle. Fracture nature of such specimens varies insignificantly.

1. (1991) Metals science and heat treatment of steel: Refer. Book. Ed. by M.L.Bernshtejn, A.G. Rakhshtadt. Vol.1: Methods of testing and research. Moscow: Metallurgiya.

2. Emelyushin, A.N., Sychkov, A.B., Sheksheev, M.A. (2012) Examination of weldability of high-strength pipe steel of K56 strength grade. Vestnik Magnitogorskogo Gos. Tekhn. Un-ta im. G.I. Nosova, Issue 3, 26-30.

3. Gulakov, S.V., Nosovsky, B.I., Novokhatskaya, A.S. et al. (2008) Method and equipment for simulation of welding(surfacing) thermal cycle. Visnyk Pryazov. Derzh. Tekhn. Un-tu, Issue 18, Pt 1, 179-183.

4. Stolyarov, V.I., Efimenko, L.A., Elagina, O.Yu. et al. (2008) Weldability of high-strength pipe steels for large diameter gas pipes. Probl. Chyorn. Metallurgii i Materialoveneniya, 3, 39-47.

5. Nazarov, A.V., Yakushev, E.V., Shabalov, I.P. et al. (2014) Comparison of weldability of high-strength pipe steels microalloyed with niobium, niobium and vanadium. Metallurgist, 57(Issue 9), 911-917.

6. Efimenko, L.A., Elagina, O.Yu., Vyshemirsky, E.M. et al. (2010) Evaluation of influence of technological and service parameters on life and safety of assembly welded joints of stop valves. Khimicheskoe i Neftegazovoe Mashinostroenie, 2, 42-45.

7. Poznyakov, V.D., Markashova, L.I., Maksimenko, A.A. et al. (2014) Effect of cyclic load on microstructure and cold resistance of 10G2FB steel HAZ metal. The Paton Welding J., 5, 2-9. 